УДК 615.076.7+574.24

\title{
ДЕТОКСИЦИРУЮЩАЯ СПОСОБНОСТЬ ГУМИНОВЫХ ВЕЩЕСТВ ТОРФОВ РАЗЛИЧНОГО ПРОИСХОЖДЕНИЯ ПО ОТНОШЕНИЮ К ИОНАМ ТЯЖЕЛЫХ МЕТАЛЛОВ
}

\author{
(C) Е.В. Акатова ${ }^{*}$ Е.Д. Дмитриева, К.В. Сюндюкова, М.М. Леонтьева, Е.Н. Музафаров
}

Тульский государственный университет, пр. Ленина, 92, Тула, 300012

(Россия), e-mail: katiaakatova@gmail.com

\begin{abstract}
Методом биотестирования с использованием дрожжей, раннее не применяемых в качестве тест-объектов в экспериментах с гуминовыми веществами, определена детоксицирующая способность гуминовых веществ торфов различного происхождения Тульской области (черноольховый низинный и сфагновый переходный) по отношению к тяжелым металлам. Выявлено влияние концентрации гуминовых веществ на рост штаммов Debaryomyces hansenii Y-1585: минимальная концентрация гуминовых веществ не оказывает стимулирующего эффекта на рост выбранных микроорганизмов, а максимальная проявляет угнетающее действие на рост тест-объекта. Детоксицирующий эффект гуминовых веществ зависит от их концентрации в растворе и проявляется в связывании ионов тяжелых металлов в нетоксичный комплекс в растворе при низких концентрациях гуминовых веществ или с адсорбированными молекулами гуминовых на поверхности клеток микроорганизмов. Коэффициенты детоксикации $(0,218-0,911)$ и константы детоксикации (для ионов свинца $0,008-0,12)$ гуминовых веществ можно использовать в качестве прогнозируемых признаков при установлении количественных зависимостей между строением гуминовых веществ и их связывающими и детоксицирующими свойствами и оценки эффективности использования анализируемых гуминовых веществ в качестве природных сорбентов для поглощения ионов тяжелых металлов.
\end{abstract}

Ключевые слова: гуминовые вещества, тяжелые металлы, детоксицирующие свойства гуминовых веществ, Debaryomyces hansenii.

Работа выполнена в рамках государственного задания №5.241.2014/К.

\section{Введение}

Тяжелые металлы относятся к наиболее широко распространенным загрязнителям окружающей среды, а по токсичности занимают одно из первых мест [1]. Среди тяжелых металлов приоритетными загрязнителями считаются кадмий, медь, цинк, свинец, попадающие в окружающую среду с техногенными выбросами, сжиганием топлива и др. Такие элементы, как ртуть, свинец, кадмий, медь, относят к критической группе веществ-индикаторов стресса окружающей среды. Таким образом, актуальными являются исследования, направленные на изучение снижения токсичности тяжелых металлов с последующим применением выявленных закономерностей в мероприятиях по ремедиации.

В последнее время уделяется большое внимание снижению токсичности тяжелых металлов гуминовыми веществами [2-7]. Гуминовые вещества (ГВ) образуются при разложении растительных и животных

Акатова Екатерина Валентиновна - доцент кафедры биотехнологии, e-mail: katiaakatova@gmail.com Дмитриева Елена Дмитриевна - доцент кафедры химии, e-mail: katiaakatova@gmail.com

Кристина Викторовна Сюндюкова - аспирант, e-mail:katiaakatova@gmail.com

Леонтьева Мария Михайловна - магистрант, e-mail: katiaakatova@gmail.com

Музафаров Евгений Назибович - профессор, заведующий кафедрой биологии, e-mail: katiaakatova@gmail.com остатков под действием биотических и абиотических факторов в условиях недостатка кислорода, поэтому они составляют основную часть горючих полезных ископаемых (каустобиолитов) - горючих сланцев, ископаемых углей, торфов.

Гуминовые вещества - это высокомолекулярные соединения переменного состава и нерегулярной структуры $[8,9]$. В естественных условиях ГВ малоактивны и практически не растворимы. Физио-

\footnotetext{
* Автор, с которым следует вести переписку.
} 
логически активной формой ГВ являются гуматы - соли гуминовых веществ, которые получают из каустобиолитов щелочной экстракцией.

Детоксицирующее действие гуматов по отношению к ионам тяжелых металлов связано с наличием в ГВ широкого набора функциональных групп (карбоксильных, гидроксильных, карбонильных и др.), ответственных за связывание ионов металлов с образованием нерастворимых комплексов [10]. Причем в большей степени комплексообразование проявляется в том случае, если в молекулах рядом с карбоксигруппой (в $\alpha-$, $\beta-$, орто-положениях) находятся электронодонорные группы - $\mathrm{NH}_{2},-\mathrm{OH},>\mathrm{C}=\mathrm{O},-\mathrm{COOH},-\mathrm{SH},>\mathrm{NH}$. Связывание ГВ с токсичными веществами приводит к снижению их концентрации в растворенной форме, а, следовательно, и к снижению токсичности этих веществ по отношению к различным организмам $[11,12]$.

Активность ГВ по отношению к различным организмам изучается в течение длительного времени. По результатам многих исследований можно заключить, что различные живые организмы положительно реагируют на присутствие малых доз ГВ в окружающей среде [2, 3, 13-15], при высоких концентрациях ГВ проявляют бактерицидное действие по отношению к живым организмам [2, 16]. Кроме того, ГВ могут выполнять и протекторную функцию, защищая живые организмы от воздействия различных токсикантов.

Таким образом, целью данного исследования являлось установление детоксицирующей способности ГВ, выделенных из торфов различного происхождения, по отношению к ионам тяжелых металлов методом биотестирования.

\section{Экспериментальная часть}

Объекты исследования. Объектами исследования являлись ГВ черноольхового низинного (ГВ ЧНТ) и сфагнового переходного торфов (ГВ СПТ), отобранных в 2013 и 2014 гг. соответственно. Характеристики торфов представлены в таблице 1 .

Выделение гуминовых веществ. Гуминовые вещества выделили по методике, рекомендованной Международным обществом по исследованию ГВ (www.ihss.gatech.edu). К навеске торфа добавляли 0,1 н раствор $\mathrm{NaOH}$ (соотношение торф : щелочь - $1: 6$ ), смесь кипятили в течение 2 ч при постоянном перемешивании и оставляли на сутки. Отстоявшуюся смесь фильтровали на складчатом фильтре. К фильтрату приливали $10 \%$ раствор $\mathrm{HCl}$ до $\mathrm{pH}=2$ (кислотность раствора определяли по лакмусовой бумаге). Полученный раствор фильтровали. Осадок (ГВ) сушили на воздухе. Очистку ГВ производили двукратным переосаждением из раствора и последующим диализом. Диализ проводили в мембранных мешках с размером пор $12-$ 14 кДа. Длительность диализа - 24 ч.

Выбор тест-объекта. В работе были использованы следующие дрожжи: Debaryomyces hansenii BKM Y-1585 (Debaryomycetaceae), Cryptococcus curvatus BKM Y-3285 (Trichosporonaceae), Pichia angusta BKM Y-2516 (Pichiaceae).

Выбор культуры дрожжей в качестве тест-объекта проводили путем посева их на чашки Петри с агаризованной средой Сабуро (пептон - 10 г/л, глюкоза - 40 г/л, агар - 20 г/л, 1 л водопроводной воды) с добавлением раствора $\mathrm{Pb}\left(\mathrm{NO}_{3}\right)_{2}$ и $\mathrm{Zn}\left(\mathrm{NO}_{3}\right)_{2}$ до конечной концентрации ионов свинца 600 мг/л, а ионов цинка 1000 мг/л. Чашки со средой без добавления солей тяжелых металлов служили контрольными. Дрожжи выращивали в течение двух суток при температуре $28{ }^{\circ} \mathrm{C}$. Культуру, которая не росла или росла незначительно в присутствии ионов тяжелых металлов, выбрали в качестве тест-объекта.

Таблица 1. Характеристики используемых торфов и мест обора проб

\begin{tabular}{l|c|c}
\hline \multicolumn{1}{c|}{ Характеристики } & Черноольховый низинный торф (ЧНТ) & Сфагновый переходный торф (СПТ) \\
\hline Место отбора проб & $\begin{array}{c}\text { Карстовое болото у поселка Майский (Тульская } \\
\text { область) глубиной 5 м, обводненное. } \\
\text { На поверхности произрастают черная ольха, } \\
\text { папоротники и осока }\end{array}$ & $\begin{array}{c}\text { Сплавина болота «Кочаки 2»у деревни } \\
\text { Ясная Поляна (Тульская область). Толщина } \\
\text { сплавины 1,5 м. На болоте растут редкие } \\
\text { березы, болотные кустарнички (андромеды } \\
\text { и клюква), пушица многоколосковая, осока } \\
\text { вздутая, камышесной }\end{array}$ \\
\hline Глубина отбора & Поверхностный слой 5-30 см & Поверхностный слой 5-30 см \\
\hline рарактеристика об- & Состав: остатки коры и древесины черной ольхи & Состав: стебли сфагновых мхов, остатки \\
& с остатками трав. Цвет черный; & осок, пушицы, и клюквы; \\
& Степень разложения 35-40\% & Степень разложения: 10-15\%; \\
& & Цвет светло-коричневый
\end{tabular}


Определение влияния гуминовых веществ на развитие тест-объекта. Биологическое действие ГВ на клетки дрожжей проводили при концентрациях 25, 35, 50, 75 и 100 мг/л в питательной среды Сабуро. В жидкую питательную среду вносились соответствующие объемы исходного раствора ГВ. Каждый опыт проводили в шестикратном повторе.

Для получения исходного раствора (500 мг/л) навеску 50 мг воздушно-сухого препарата ГВ растворяли в 70 мл 0,05 н раствора $\mathrm{NaOH}$ в течение суток. Затем этот раствор доводили до $\mathrm{pH}=6,5$ 0,1M раствором $\mathrm{HNO}_{3}$ и снова оставляли на сутки. Если заданное значение $\mathrm{pH}$ не изменилось, раствор переносили в мерную колбу на 100 мл и доводили дистиллированной водой до метки [17].

Тест-функцией служил выход сырой биомассы, полученный после осаждения культуры центрифугированием (10 мин при $8000 \mathrm{xg})$.

Определение токсического действия ионов $\mathrm{Pb}(\mathrm{II})$ u $\mathrm{Zn}(\mathrm{II})$. Токсичное действие ионов свинца на клетки дрожжей изучалось при концентрации 30, 60, 90, 120, 150, 300 и 600 мг/л ионов металла в питательной среде (что соответствует 1-20 ОДК для свинца в почвах [18]). Токсичное действие ионов цинка на клетки дрожжей изучалось при концентрации 50, 100, 160, 200, 250, 500 и 1000 мг/л металла в питательной среде (что соответствует 1-20 ОДК для свинца в почвах [18]).

Для определения токсичного действия ионов тяжелых металлов в пробирки с 10 мл стерильной среды Сабуро добавляли соответствующие количество растворов солей $\mathrm{Pb}\left(\mathrm{NO}_{3}\right)_{2}$ и $\mathrm{Zn}\left(\mathrm{NO}_{3}\right)_{2}$, доведенных до $\mathrm{pH}=4$ 0,1M раствором $\mathrm{HNO}_{3}$ для получения необходимой концентрации ионов металла в среде. Пробирки заражали инокулятом предварительно выращенных микроорганизмов. В качестве контроля выступала среда без добавления солей тяжелых металлов. Каждый опыт проводили в трехкратном повторе. Дрожжи выращивали в течение суток при $28^{\circ} \mathrm{C}$ в шейкере-инкубаторе при аэрации 180 об/мин.

Влияние ионов тяжелых металлов на развитие тест-объекта фиксировали по значению оптической плотности культуральной среды при длине волны 590 нм.

Определение детоксищиующих свойств гуминовых веществ по отношению к ионам Pb(II) u Zn(II). Детоксицирующие свойства ГВ по отношению к ионам $\mathrm{Pb}(\mathrm{II})$ и $\mathrm{Zn}(\mathrm{II})$ определяли по росту дрожжей в богатой среде Сабуро с добавлением солей этих металлов в выбранной концентрации и добавлением ГВ с концентрацией $25,35,50,75$ и 100 мг/л. Каждый опыт проводили в шестикратном повторе. Тест-функцией служил выход сырой биомассы дрожжей, полученный после осаждения культуры центрифугированием (10 мин при 8000 xg).

Количественную оценку детоксицирующих свойств ГВ устанавливали по коэффициенту детоксикации D [19]:

$$
D=1-\frac{R_{0}\left(R_{\Gamma B}-R_{M e+\Gamma B}\right)}{R_{\Gamma B}\left(R_{0}-R_{M e}\right)}
$$

где $\mathrm{R}_{0}$ - тест-отклик в контроле (без добавления ионов тяжелых металлов и гуминовых веществ); $\mathrm{R}_{\Gamma в}-$ тест-отклик в присутствиигуминовых веществ; $\mathrm{R}_{\mathrm{Me}}$ - тест-отклик в присутствии ионов тяжелых металлов; $\mathrm{R}_{\mathrm{Me}+г в}$ - тест-отклик в присутствии ионов тяжелых металлов и гуминовых веществ.

\section{Обсуждение результатов}

Bыбор тест-объекта. В литературе неоднократно встречается информация об использовании дрожжей в экспериментах с ГВ [20-22], а также отмечалась стимулирующая активность ГВ по отношению к этим организмам [3]. Поэтому в данной работе выбирали тест-организм из представителей нескольких родов дрожжей (коллекция лаборатории).

Для культивирования клеток дрожжей использовали стандартную, сбалансированную по микроэлементам и насыщенную питательными веществами среду для дрожжей (среда Сабуро). Это позволяет говорить о том, что дрожжи культивировались в оптимальных для их роста условиях, и позволяет избежать ситуации, когда микроорганизмы испытывают «голодание» или по исчерпании «основного» источника питания микроорганизмы переходят на «альтернативный», что в свою очередь сопровождается перестройкой метаболизма и труднообъяснимым поведением культуры.

По визуальным данным роста дрожжей на агаризованной питательной среде Сабуро, содержащей ионы тяжелых металлов, обнаружили, что штамм C. Curcatus BКМ Y-3288 показывает активный рост. Это 
свидетельствует об устойчивости этого штамма к данным концентрациям ионов тяжелых металлов. Штамм P. angusta ВКМ Y-2518 оказался более чувствительной к этим концентрациям ионов и рост был незначительным, а D. hansenii ВКМ Y-1585 не рос при данных концентрациях. На основании визуального анализа роста этих микроорганизмов был выбран штамм D. hansenii BКM Y-1585 в качестве тест-культуры для дальнейших экспериментов.

Определение диапазона токсичности ионов $\mathrm{Pb}(\mathrm{II})$ u $\mathrm{Zn}(\mathrm{II})$. Токсичное действие ионов тяжелых металлов на клетки дрожжей изучалось при росте тест-культуры в среде с добавлением различных концентраций ионов свинца и цинка (рис. 1).

Из рисунка 1 видно, что увеличение концентрации ионов тяжелых металлов в культуральной среде приводит к уменьшению оптической плотности раствора, а, следовательно, и к снижению роста биомассы. Таким образом, чувствительность Debaryomyce shansenii Y-1585по отношению кионам $\mathrm{Pb}$ (II) и $\mathrm{Zn}(\mathrm{II})$ в культуральной среде более 150 мг/л. Для дальнейшего изучения детоксицирующей способности ГВ по отношению в ионам $\mathrm{Pb}(\mathrm{II})$ и $\mathrm{Zn}(\mathrm{II})$ анализировали следующие концентрации: для ионов $\mathrm{Pb}(\mathrm{II})$ выбрали концентрацию 120 мг/л, что соответствует четырехкратному превышению ОДК, а для ионов $\mathrm{Zn}$ (II) 150 мг/л, что соответствует трехкратному превышению ОДК [18]. Выбор концентрации обусловлен снижением биомассы на предельных концентрациях, при которых выход биомассы снижается на треть от контрольного значения (значения выхода биомассы при этих концентрациях представлен на рисунке 3).

Влияние гуминовых веществ на рост дрожжей. Биологическое действие ГВ на клетки дрожжей в данной работе изучалось при концентрации 25 мг/л, что соответствует максимальному содержанию ГВ в природных водах, концентрации 35, 50, 75 и 100 мг/л гуминовых веществ были выбраны экспериментальным путем на основании эксперимента по изучению образования нерастворимых гуматов свинца [23]. Результаты исследования приведены на рисунке 2.

Из рисунка 2 видно, что при добавлении в питательную среду ГВ в концентрациях 25-35 мг/л выход биомассы микроорганизмов близок к контролю. Увеличение содержания ГВ в культуральной среде приводит к снижению выхода биомассы микроорганизмов. Подобная зависимость отмечена в других работах $[19,21]$. Снижение выхода биомассы дрожжей происходит вследствие формирования плотного полимолекулярного слоя, состоящего из молекул ГВ, сорбированного на поверхности и внутри клеточной стенки дрожжей, который препятствует нормальному обмену веществ между клеткой и питательным раствором и приводит к снижению роста [22].

Определение детоксицирующего влияния гуминовых веществ на рост дрожжей в присутствии ионов $\mathrm{Pb}(\mathrm{II})$ и $\mathrm{Zn}(\mathrm{II})$. Изучение детоксицирующего влияния ГВ, выделенных из торфов различного происхождения, по отношению к ионам Pb(II) и Zn(II) на рост Debaryomyces hansenii BKM Y-1585 проводили в жидкой питательной среде с добавлением различных концентраций ГВ (ЧНТ и СПТ), а также 120 мг/л ионов Рb(II) или 150 мг/л ионов Zn(II). Результаты представлены на рисунке 3.

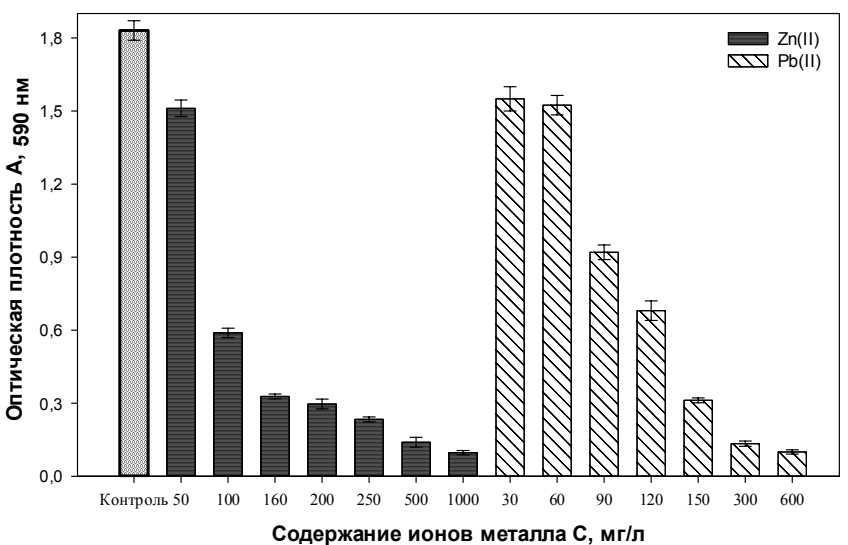

Рис. 1. Оптическая плотность культуры Debaryomyces hansenii Y-1585, выросшей при различных концентрациях ионов $\mathrm{Pb}(\mathrm{II})$ и $\mathrm{Zn}(\mathrm{II})$ в культуральной среде $(\mathrm{n}=6, \mathrm{P}=0,95)$

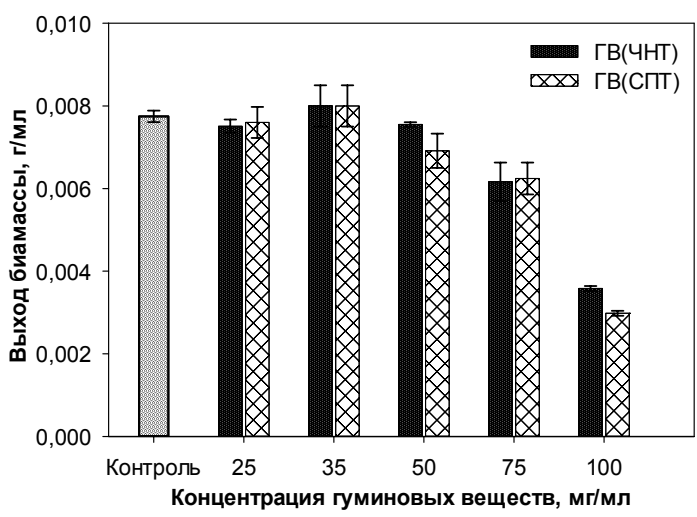

Puc. 2. Зависимость выхода биомассы дрожжей Debaryomyces hansenii Y-1585 от концентрации гуминовых веществ в культуральной среде. Контроль - выход биомассы, выращенной на среде без добавления ГВ $(\mathrm{n}=6, \mathrm{P}=0,95)$ 
Из полученной зависимости (см. рис. 3) видно, что добавление ГВ в культуральную среду, содержащую ионы цинка и свинца, приводит к увеличению выхода биомассы по сравнению с выходом из культуральной среды, содержащей ионы $\mathrm{Pb}(\mathrm{II})$ и $\mathrm{Zn}(\mathrm{II})$, без добавления ГВ. Количество биомассы зависит как от концентрации ГВ в растворе, так и от типа иона тяжелого металла.

Выход биомассы дрожжей, выросшей на культуральной среде в присутствии ионов $\mathrm{Pb}(\mathrm{II})$, зависит от концентрации ГВ в растворе, причем при концентрации 75 мг/л наблюдается зависимость от объекта выделения ГВ и их фракционного состава - степени дисперсности. В среде, содержащей ГВ сфагнового переходного торфа, выход биомассы дрожжей больше, чем в присутствии ГВ черноольхового низинного торфа.

Ранее [23] было установлено, что все анализируемые ГВ имеют полимодальное распределение: гуминовые вещества ЧНТ содержат высокомолекулярные фракции с массой выше 75 кДа и фракции с молекулярными массами в диапазоне от 4 до 39 кДа, гуминовые вещества СПТ содержат в своем составе более низкомолекулярные фракции с молекулярными массами от 3 до 38 кДа.

Увеличение выхода биомассы при культивировании дрожжей в присутствии ионов $\mathrm{Pb}(\mathrm{II})$ с увеличением концентрации ГВ связано с несколькими причинами. Во-первых, связывание в нерастворимые гуматы металлов с ГВ как в растворе, так и сорбированными на поверхности клеток микроорганизмов, вовторых, десорбцией нерастворимых гуматов с поверхности клеток в раствор снижает токсичность тяжелых металлов на организм. В-третьих, оставшиеся в растворе ГВ способны оказывать стимулирующий эффект на рост микроорганизмов [3, 24].

При добавлении ГВ в культуральную среду, содержащую ионы $\mathrm{Zn}(\mathrm{II})$, максимальное увеличение выхода биомассы наблюдается при концентрации ГВ 25 мг/л и 100 мг/л. В первом случае это связано со связыванием ионов тяжелых металлов в нерастворимый комплекс металл - ГВ, а во втором случае, помимо связывания ионов тяжелых металлов, может накладываться и стимулирующий эффект оставшихся в растворе ГВ на рост микроорганизмов, а также десорбция нерастворимых гуматов цинка с поверхности клеточной стенки микроорганизмов. При концентрации 50 и 75 мг/л детоксицирующий эффект проявляется не так ярко. Возможно, так происходит потому, что идет связывание ионов металла с ГВ, сорбированными на поверхности клеток микроорганизмов, что препятствует нормальному питанию и развитию клеток.

Ионы $\mathrm{Pb}(\mathrm{II})$ и $\mathrm{Zn}(\mathrm{II})$ в сложных системах, какой является среда для выращивания микроорганизмов, могут существовать в различных формах, поэтому для описания ионных равновесий пользовались распределительными диаграммаи зависимости ионов от $\mathrm{pH}$ растворов [25]. При $\mathrm{pH}$ меньше 6 основная часть ионов $\mathrm{Pb}(\mathrm{II})$ и $\mathrm{Zn}(\mathrm{II})$ находится в растворе виде гидратированных ионов $\mathrm{Pb}^{2+}$ и $\mathrm{Zn}^{2+}$, а при рН в диапазоне 6,5-9 в растворе в равных долях сосуществуют свободные ионы $\mathrm{Pb}^{2+}$ и $\mathrm{Zn}^{2+}$ и их гидроксокатионы $\mathrm{PbOH}^{+}$ и $\mathrm{ZnOH}^{+}$. В условиях эксперимента при добавлении различных концентраций солей этих металлов происходило изменение $\mathrm{pH}$ среды максимально с 7,2 до 6,2. Данное изменение $\mathrm{pH}$ среды несущественно влияет на рост микроорганизов, а тяжелые металлы присутствовали в среде как $\mathrm{Me}^{2+}$, так и МеОН $\mathrm{H}^{+}$При добавлении в среду, содержащую соли тяжелых металлов, различных концентраций ГВ не происходит дополнительному изменения рН среды. Очевидно ГВ связываются с $\mathrm{Me}^{2+}$ по ионного механизму с выделением в среду протона в эквивалентных количествах, при этом гидроксокатионы переходят в гидратированные ионы. Сами ГВ в этом диапазоне рН будут частично депротонированы [26], а их связывающая способность по отношению к ионам тяжелых металлов максимальна.

Количественная оценка детоксииирующих свойств гуминовых вещчеств. Неоднократно отмечалось, что детоксицирующее действие ГВ по отношению к различным токсикантам может быть связано с непосредственным их взаимодействием с ГВ, в результате чего происходит связывание и образование комплекса токсикант - ГВ, однако сами ГВ оказывают действие на биологический объект, стимулируя или замедляя развитие организма $[2,3,19,24]$. Поэтому стимулирующее действие ГВ при росте тест-объекта в присутствии токсиканта может быть обусловлено этими двумя причинами.

Для количественной оценки детоксицирующих свойств ГВ используют такие количественные параметры, как коэффициент детоксикации и константа детоксикации [19]. Коэффициент детоксикации отражает изменение уровня токсичности вещества в присутствии ГВ по сравнению с токсичностью в их отсутствие с учетом возможного изменения тест-отклика под действием собственного воздействия ГВ. Учитывая, что чувствительность тест-объектов к действию ГВ не изменяется в присутствии токсиканта, использование коэффициента детоксикации позволяет охарактеризовать детоксцирующий эффект ГВ, обусловленный только связыванием токсиканта в нетоксичные комплексы, на фоне их стимулирующего действия 
на тест-объекты. Поэтому для количественной оценки детоксицирующего действия гуминовых веществ рассчитывали коэффициент детоксикации D (табл. 2, рис. 4).

При расчете коэффициента детоксикации учитывали влияние гуминовых веществ на рост микроорганизмов. Полученные значения коэффициентов детоксикации не зависят от происхождения гуминовых веществ, но зависят от их концентрации в растворе культуральной среды. Для ионов свинца зависимость коэффициента детоксикации от концентрации гуминовых веществ изменяется линейно, а для ионов цинка имеет полиморфный вид и не позволяет рассчитать константу детоксикации по отношению к ионам Zn(II), которая представляет собой тангенс угла наклона в линейной зависимости изменения коэффициента детоксикации от концентрации гуминовых веществ. Рассчитанная константа детоксикации гуминовых веществ, независимо от их происхождения, по отношению к ионам $\mathrm{Pb}(\mathrm{II})$ составила 0,01 .

На основании полученных данных можно сделать вывод, что решающей является способность ГВ к связыванию металла в нетоксичный комплекс, а снятие токсического эффекта оказывает влияние более высокая концентрация ГВ. Последнее можно объяснить тем, что в эксперименте использовали достаточно высокие концентрации ионов металла.

Таблица 2. Коэффициенты детоксикации ГВ различного происхождения

\begin{tabular}{|c|c|c|c|c|}
\hline \multirow{2}{*}{$\begin{array}{c}\text { Концентрация ГВ, } \\
\text { мг/л }\end{array}$} & \multicolumn{2}{|c|}{ ГВ(СПТ) } & \multicolumn{2}{|c|}{ ГВ(ЧНТ) } \\
\hline & $\mathrm{Zn}$ (II) $150 \mathrm{мг/л}$ & $\mathrm{Pb}$ (II) $120 \mathrm{мг/л}$ & $\mathrm{Zn}$ (II) 150мг/л & $\mathrm{Pb}$ (II) 120 мг/л \\
\hline 25 & 0,6248 & 0,2686 & 0,6726 & 0,2815 \\
\hline 35 & H.O. & 0,3622 & H.O. & 0,3479 \\
\hline 50 & 0,2901 & 0,6829 & 0,1474 & 0,5574 \\
\hline 75 & 0,1811 & 1,2179 & 0,3145 & 0,9299 \\
\hline 100 & 2,7418 & - & 2,2734 & - \\
\hline
\end{tabular}

Примечание: Н.О. - не обнаружено; - исследования не проводили.

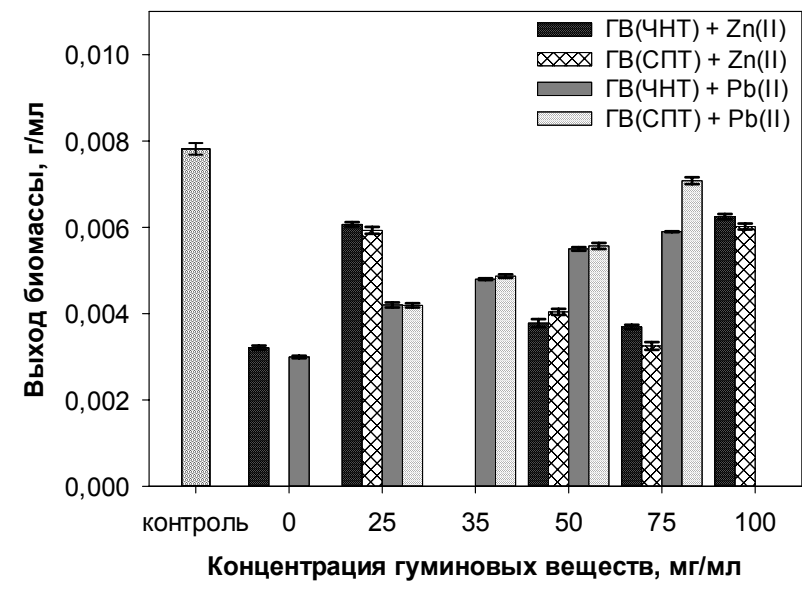

Рис. 3. Зависимость выхода биомассы дрожжей Debaryomyces hansenii Y-1585 от концентрации гуминовых веществ в культуральной среде, содержащей соли тяжелых металлов (Zn(II) - 150 мг/л, $\mathrm{Pb}(\mathrm{II})$ - 120 мг/л). Контроль - выход биомассы, выращенной на среде без добавления ГВ и солей тяжелых металлов $(\mathrm{n}=6, \mathrm{P}=0,95)$

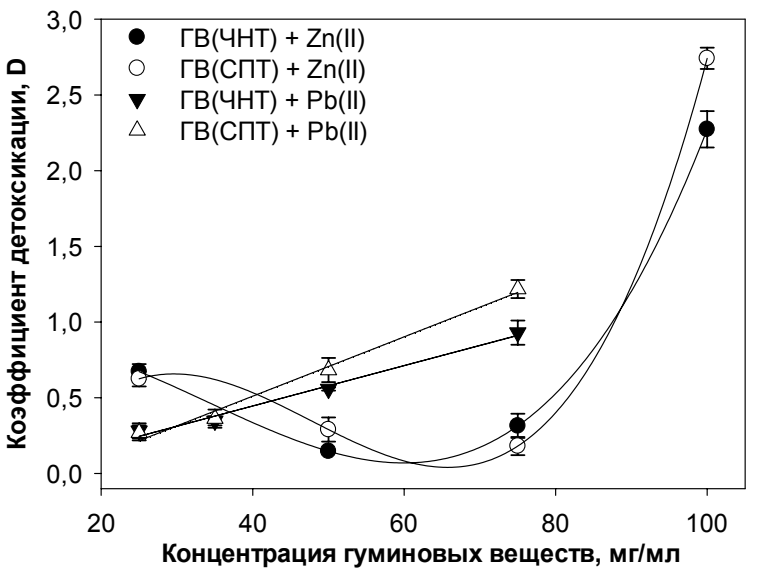

Рис. 4. Зависимость коэффициента детоксикации от концентрации гуминовых веществ

\section{Выводы}

1. Скрининг микроорганизмов показал, что наиболее чувствительным к воздействию ионов $\mathrm{Pb}(\mathrm{II})$, $\mathrm{Zn}(\mathrm{II})$ оказался только микроорганизм Debaryomyces hansenii Y-1585, выбранный в качестве тест-объекта для изучения детоксицирующей способности гуминовых веществ. 
2. Определены диапазон токсичности ионов $\mathrm{Pb}(\mathrm{II}), \mathrm{Zn}(\mathrm{II})$ на выбранный тест-объект и аналитическая концентрация металла, при которой наблюдается незначительный рост микроорганизма: 4 ОДК ионов $\mathrm{Pb}(\mathrm{II})$ (120 мг/л), 3 ОДК ионов Zn(II) (150 мг/л).

3. Установлено, что исследуемые гуминовые вещества не оказали стимулирующего эффекта на рост выбранного штамма микроорганизма, а при высоких концентрациях в культуральной среде проявили отрицательное воздействие на тест-объект, что связано с образованием объемного полимолекулярного слоя на поверхности клеточной стенки дрожжей, препятствующему нормальному обмену веществ между клеткой и питательным раствором.

4. Определены коэффициенты детоксикации $(0,218-0,911)$ и константы детоксикации (для ионов свинца 0,008-0,12) гуминовых веществ. Эти значения можно использовать в качестве прогнозируемых признаков при установлении количественных зависимостей между строением гуминовых веществ и их связывающими и детоксицирующими свойствами и оценки эффективности использования анализируемых гуминовых веществ в качестве природных сорбентов для поглощения ионов тяжелых металлов.

\section{Сиисок литературы}

1. Дабахов М.В., Дабахова Е.В., Титова В.И. Тяжелые металлы: экотоксикология и проблемы нормирования. Н.Новгород, 2005. 165 с.

2. Куликова Н.А. Защитное действие гуминовых веществ по отношению к растениям в водной и почвенной средах в условиях абиотических стрессов : автореф. дис. ... д-ра биол. наук. М., 2008. 48 с.

3. Семенов А.А. Влияние гуминовых кислот на устойчивость растений и микроорганизмов к воздействию тяжелых металлов : автореф. дис. ... канд. биол. наук. М., 2009. 25 с.

4. Tarasova A.S., Kislan S.L., Fedorova E.S., Kuznetsov A.M., Mogilnaya O.A., Stom D.I., Kudryasheva N.S. Bioluminescence as a tool for studying detoxification processes in metal salt solutions involving humic substances // Journal of photochemistry and photobiology B. 2012. Vol. 117. Pp. 164-170.

5. Sachs S., Bernhard G. Humic acid model substances with pronounced redox functionality for the study of environmentally relevant interaction processes of metal ions in the presence of humic acid // Geoderma. 2011. Vol. 162. Pp. 132-140.

6. Zhilin D., Schmitt-Kopplin P., Perminova I. Reduction of Cr(VI) by peat and coal humic substances // Environ. Chem. Lett. 2004. Vol. 2. Pp. 141-145.

7. $\mathrm{Gu}$ B., Chen J. Enhanced microbial reduction of $\mathrm{Cr}(\mathrm{VI})$ and $\mathrm{U}(\mathrm{VI})$ by different natural organic matter fractions // Geochim. Cosmochim. Acta. 2003. Vol. 67. Pp. 3575-3582.

8. Орлов Д.С. Гумусовые кислоты почв и общая теория гумификации. М., 1990. 325 с.

9. Перминова И.В. Гуминовые вещества - вызов химикам XXI века // Химия и жизнь - XXI век. 2008. №1. C. 50-55.

10. Kaschl A., Chen Y. Interaction of humic substances with trace metals and their stimulatory effects on plant growth // Use of humic substances to remediate polluted environments: from theory to practice. 2005. Vol. 52. Pp. 83-115.

11. Suffet I.H., MacCarthy P. Aquatic Humic Substances: Influence on Fate and Treatment of Pollutants. American Chemical Society, Advances in Chemistry Series. 1989. Vol. 219. 886 p.

12. Chiou C.T., Kile D.E., Brinton T.I., Malcolm R.L. A comparison of water solubility enhancements of organic solutes by aquatic humic materials and commercial humic acids // Environ. Sci. Technol. 1987. Vol. 21. Pp. 1231-1234.

13. Христева Л.А. Об участии гуминовых кислот и других органических веществ в питании высших растений // Почвоведение. 1953. №10. С. 24-29.

14. Орлов Д.С. Свойства и функции гуминовых веществ // Гуминовые вещества в биосфере. М., 1993. С. 16-27.

15. Попов А.И. Гуминовые вещества: свойства, строение, образование. СПб., 2004. 248 с.

16. Дмитриева Е.Д., Платонов В.В., Проскуряков В.А., Сыпченко А.Я., Хадарцев А.А. Биологическая активность сапропеля и препаратов на его основе. Деп. В ВИНИТИ 03.07.2003 - № 1262 В. 2003. 20 с.

17. Семенов А.А. Влияние гуминовых кислот на устойчивость растений и микроорганизмов к воздействию тяжелых металлов. М., 2009. 46 с.

18. Гигиенические нормативы ГН 2.1.7.2511-09 «Ориентировочно допустимые концентрации (ОДК) химических веществ в почве». Дата введения 1.07.2009 г. М., 2009. 10 с.

19. Пермитова И.В. Анализ, классификация и прогноз свойств гумусовых кислот : дис. ... д-ра хим. наук. М., 2000. $359 \mathrm{c}$.

20. Мажуль В.М., Прокопова Ж.В., Ивашкевич Л.С. Механизм действия гуминовых препаратов из торфа на структурное состояние мембран и функциональную активность клеток дрожжей // Гуминовые вещества в биосфере. М., 1993. С. 151-157.

21. Стрелков В.М., Гайлитис Ю.Н., Шмит У.Я. Стимулирующее влияние продуктов механохимической деструкции гуминовых веществ торфа на рост кормовых дрожжей // Научные доклады высшей школы. Серия биологические науки. 1991. №10. С. 81-87. 
22. Овчинникова Т.Ф., Кудряшов А.П., Мажуль В.М., Наумова Г.В., Райцина Г.И. О мембранотропной активности гидрогумата - гуминового препарата из торфа // Научные доклады высшей школы. Серия. Биологические науки. 1991. №10. С. 103-109.

23. Дмитриева Е.Д., Горячева А.А., Сюндюкова К.В., Акатова Е.В. Фракционирование гуминовых веществ, выделенных из торфов различного происхождения электрофоретическим методом // Известия ТулГУ, Естественные науки. 2015. Вып. 3. С. 243-248.

24. Семенов А.А., Демин В.В., Бирюков М.В., Завгородняя Ю.А. Локализация биопротекторного действия гуминовых веществ в почвах // Естественные технические науки. 2008. №4. С. 84-93.

25. Справочник химика: Т. 3. Химическое равновесие и кинетика. Свойства растворов. Электродные процессы / под ред. Б.П. Никольского. М., 1965. 1008 с.

26. Каюгин А.А. Распределение кадмия в модельных системах, содержащих каолинит и гуминовые кислоты : автореф. дис. ... канд. хим. наук. Тюмень, 2009. 23 с.

Поступило в редакцию 22 июня 2016 г.

После переработки 19 октября 2016 г.

Akatova E.V.*, Dmitrieva E.D., Siundiukova K.V., Leontieva M.M., Muzafarov E.N. DETOXIFYING CAPACITY OF HUMIC SUBSTANCES FROM DIFFERENT ORIGIN PEATS OF THE TULA REGION IN RELATION TO HEAVY METAL IONS

Tula State University, pr. Lenina, 92, Tula, 300012 (Russia), e-mail:. Katiaakatova@gmail.com

Detoxifying capacity of humic substances from different origin peats of the Tula region (black Alder fen peat and Sphagnum transition peat) in relation to heavy metals was determined by biotesting method using the yeast that had not been used previously as the test-objects in experiments with humic substances. The effect of the concentration of humic substances on the growth of Debaryomyces hansenii strain Y-1585 was revealed: the minimum concentration of humic substances does not have any stimulating effect on the growth of selected microorganisms, and the maximum concentration of humic substances shows the inhibitory action on the growth of the test object. Detoxifying effect of humic substances depends on their concentration in solution and manifests in the binding of heavy metal ions in a non-toxic complex in solution at low concentrations of humic substances or with humic substances adsorbed on the surface of microorganism's cells. Detoxifying coefficients $(0,218-$ 0,911 ) and detoxifying constants (there are $0,008-0,12$ for lead ions) of humic substances can be used as the predicted signs in establishing quantitative relationships between the structure of humic substances, their binding and detoxifying properties and efficacy evaluation of the use of analyzed humic substances as natural sorbents for absorption of heavy metal ions.

Keywords: humic substances, heavy metals, detoxifying properties of humic substances, Debaryomyces hansenii.

\footnotetext{
* Corresponding author.
} 


\section{References}

1. Dabakhov M.V., Dabakhova E.V., Titova V.I. Tiazhelye metally: ekotoksikologiia i problemy normirovaniia. [Heavy metals: Ecotoxicology and valuation issues]. N.Novgorod, 2005, 165 p. (in Russ.).

2. Kulikova N.A. Zashchitnoe deistvie guminovykh veshchestv po otnosheniiu $k$ rasteniiam $v$ vodnoi $i$ pochvennoi sredakh $v$ usloviiakh abioticheskikh stressov: avtoref. dis. ... d-ra biol. nauk. [The protective effect of humic substances to the plants in the water and soil media under abiotic stresses: Abstract. Dis. ... Dr. biol. sciences]. Moscow, 2008, 48 p. (in Russ.).

3. Semenov A.A. Vliianie guminovykh kislot na ustoichivost' rastenii i mikroorganizmov $k$ vozdeistviiu tiazhe-lykh metallov: avtoref. dis. ... kand. biol. nauk. [Effect of humic acid on the resistance of plants and micro-organisms to the effects of heavy metals: Abstract. Dis. ... Cand. biol. sciences]. Moscow, 2009, 25 p. (in Russ.).

4. Tarasova A.S., Kislan S.L., Fedorova E.S., Kuznetsov A.M., Mogilnaya O.A., Stom D.I., Kudryasheva N.S. Journal of photochemistry and photobiology B, 2012, vol. 117, pp. 164-170.

5. Sachs S., Bernhard G. Geoderma, 2011, vol. 162, pp. 132-140.

6. Zhilin D., Schmitt-Kopplin P., Perminova I. Environ. Chem. Lett., 2004, vol. 2, pp. 141-145.

7. Gu B., Chen J. Geochim. Cosmochim. Acta., 2003, vol. 67, pp. 3575-3582.

8. Orlov D.S. Gumusovye kisloty pochv $i$ obshchaia teoriia gumifikatsii. [Humic acid soils and the general theory of humification]. Moscow, 1990, 325 p. (in Russ.).

9. Perminova I.V. Khimiia i zhizn'-XXI vek, 2008, no. 1, pp. 50-55. (in Russ.).

10. Kaschl A., Chen Y. Use of humic substances to remediate polluted environments: from theory to practice, 2005, vol. 52, pp. 83-115.

11. Suffet I.H., MacCarthy P. Aquatic Humic Substances: Influence on Fate and Treatment of Pollutants. American Chemical Society, Advances in Chemistry Series, 1989, vol. 219, 886 p.

12. Chiou C.T., Kile D.E., Brinton T.I., Malcolm R.L. Environ. Sci. Technol., 1987, vol. 21, pp. 1231-1234.

13. Khristeva L.A. Pochvovedenie, 1953, no. 10, pp. 24-29. (in Russ.).

14. Orlov D.S. Guminovye veshchestva vbiosfere. [Humic substances in the biosphere]. Moscow, 1993, pp. 16-27. (in Russ.).

15. Popov A.I. Guminovye veshchestva: svoistva, stroenie, obrazovanie. [Humic substances: properties, structure, education]. St. Petersburg, 2004, 248 p. (in Russ.).

16. Dmitrieva E.D., Platonov V.V., Proskuriakov V.A., Sypchenko A.Ia., Khadartsev A.A. Biologicheskaia aktivnost' sapropelia i preparatov na ego osnove. [The biological activity of sapropel and preparations based on it]. Dep. V VINITI 03.07.2003 - № 1262 V. 2003, 20 p. (in Russ.).

17. Semenov A.A. Vliianie guminovykh kislot na ustoichivost' rastenii $i$ mikroorganizmov $k$ vozdeistviiu tiazhelykh metallov. [Influence of humic acids and microbial plant resistance to the effects of heavy metals]. Moscow, 2009, 46 p. (in Russ.).

18. Gigienicheskie normativy GN 2.1.7.2511-09. Orientirovochno dopustimye kontsentratsii (ODK) khimicheskikh veshchestv v pochve. [Hygienic standards GN 2.1.7.2511-09. Roughly permissible concentration (APC) of chemicals in the soil.]. Moscow, 2009, 10 p. (in Russ.).

19. Permitova I.V. Analiz, klassifikatsiia i prognoz svoistv gumusovykh kislot:dis. ... d-ra khim. nauk. [Analysis, classification and prediction of the properties of humic acids: dis. ... Dr. chem. Sciences]. Moscow, 2000, 359 p. (in Russ.).

20. Mazhul' V.M., Prokopova Zh.V., Ivashkevich L.S. Guminovye veshchestva v biosfere. [Humic substances in the biosphere]. Moscow, 1993, pp. 151-157. (in Russ.).

21. Strelkov V.M., Gailitis Iu.N., Shmit U.Ia. Nauchnye doklady vysshei shkoly. Seriia biologicheskie nauki, 1991, no. 10, pp. 81-87. (in Russ.).

22. Ovchinnikova T.F., Kudriashov A.P., Mazhul' V.M., Naumova G.V., Raitsina G.I. Nauchnye doklady vysshei shkoly. Seriia biologicheskie nauki, 1991, no. 10, pp. 103-109. (in Russ.).

23. Dmitrieva E.D., Goriacheva A.A., Siundiukova K.V., Akatova E.V. Izvestiia TulGU. Estestvennye nauki, 2015, no. 3, pp. 243-248. (in Russ.).

24. Semenov A.A., Demin V.V., Biriukov M.V., Zavgorodniaia Iu.A. Estestvennye tekhnicheskie nauki, 2008, no. 4, pp. 84-93. (in Russ.).

25. Spravochnik khimika: T. 3. Khimicheskoe ravnovesie i kinetika. Svoistva rastvorov. Elektrodnye protsessy [Directory of Chemical: T. 3. Chemical equilibrium and kinetics. The properties of the solutions. Electrode processes]. ed. B.P. Nikol'skiy. Moscow, 1965, 1008 p. (in Russ.).

26. Kaiugin A.A. Raspredelenie kadmiia v model'nykh sistemakh, soderzhashchikh kaolinit i guminovye kisloty: avtoref. dis. ... kand. khim. nauk. [Distribution of cadmium in model systems containing kaolinite and humic acids: Abstract. Dis. ... Cand. Chem. Sciences]. Tiumen', 2009, 23 p. (in Russ.). 
